\title{
First description of the male of Thaida chepu Platnick, 1987 (Araneae, Austrochilidae) with micro-computed tomography of the palpal organ
}

\author{
Peter Michalik ${ }^{1,2}$, Martin J. Ramírez ${ }^{3}$ \\ I Allgemeine und Systematische Zoologie, Zoologisches Institut und Museum, Ernst-Moritz-Arndt-Universität, \\ J.-S.-Bach-Str. 11/12, D-17489 Greifswald, Germany 2 Research Associate, Division of Invertebrate Zoology, \\ American Museum of Natural History, Central Park West at 79th Street, New York, NY 10024, USA 3 Museo \\ Argentino de Ciencias Naturales - CONICET, Buenos Aires, Argentina \\ Corresponding author: Peter Michalik (michalik@uni-greifswald.de) \\ Academic editor: Jeremy Miller | Received 30 July 2013 | Accepted 30 October 2013 | Published 19 November 2013 \\ Citation: Michalik P, Ramírez MJ (2013) First description of the male of Thaida chepu Platnick, 1987 (Araneae, \\ Austrochilidae) with micro-computed tomography of the palpal organ. ZooKeys 352: 117-125. doi: 10.3897/ \\ zookeys.352.6021
}

\begin{abstract}
The male of the austrochilid spider Thaida chepu Platnick, 1987 is described for the first time. We analyzed the internal anatomy of the palpal organ by using micro-computed tomography to investigate the spermophor as well as the muscles and tendons in the cymbium and tibia in detail. As shown by our data, muscles 29 and 30 originate in the tibia and continue with tendons to the base of the bulb, which resembles the ancestral organization for the male palp of spiders; this condition has not been described for Araneomorphae until now. The 3D reconstruction of the spermophor confirms recent interpretations of the male palp sclerites within Austrochilidae.
\end{abstract}

\section{Keywords}

Taxonomy, micro-CT, spermophor, palp 


\section{Introduction}

The family Austrochilidae consists of three genera with a very peculiar distribution. Whereas the genera Austrochilus Gertsch \& Zapfe, 1955 (6 species) and Thaida Karsch, 1880 (2 species) are endemic to the forests of Central and Southern Chile and adjacent Argentina, the monotypic genus Hickmania Gertsch, 1958 is endemic to Tasmania (Forster et al. 1987). The Austrochilidae, which together with the family Gradungulidae comprise the superfamily Austrochiloidea, are of high interest for spider systematics since it is ambiguously placed among the early derivative taxa of Araneomorphae (e.g., Griswold et al. 2005). Thus, detailed knowledge of taxon-specific structures such as the genitalia is highly valuable not only for species determination but also for a better understanding of interrelationships among the Araneomorphae. In the present study, we describe the male of Thaida chepu Platnick, 1987 for the first time. Furthermore, we studied the internal anatomy of the male palpal organ using X-ray microtomography (micro-CT) in order to reconstruct the spermophore (sperm duct) and position of the embolus, which was debated in former studies (see Griswold et al. 2005: 17).

\section{Material and methods}

We collected a male of $T$. chepu close to the type locality in a wet lowland mixed forest at Lago Huillinco (Chiloé, Chile) (Fig. 1). The material was examined and documented (extended focal range images) in $80 \%$ ethanol using a Zeiss Discovery V20 stereo microscope with a Zeiss MCr camera. Editing of images to adjust brightness, contrast and color was performed using Adobe Photoshop CS4. Measurements (given in millimeters) were obtained from digital images using the IntMess module in the program Zeiss AxioVision 4.8 (Carl Zeiss MicroImaging $\mathrm{GmbH}$, Göttingen, Germany). The style of the description is based on Forster et al. (1987) and Grismado et al. (2003).

For the micro-CT analyses of the male palp, the sample was dehydrated in graded ethanol and stained with a $1 \%$ iodine solution for 12 hours. After washing in pure ethanol, the sample was scanned in ethanol with an Xradia MicroXCT-200 X-ray imaging system (Carl Zeiss X-ray Microscopy Inc., Pleasanton, USA) at $40 \mathrm{kV}$ and $8 \mathrm{~W}$ using phase contrast (4.0 scintillator-objective lens unit, $15 \mathrm{~s}$ exposure time, $4.15 \mu \mathrm{m}$ pixel size). The obtained data were processed using the 3D analysis software AMIRA v. 5.4.2 (Visage Imaging, Berlin, Germany). Virtual reconstruction of the spermophore was performed by delineation in each section (segmentation) and a smooth surface was computed using the surface editor. The image stack is stored in MorphDBase under creative commons attribution (CC-BY; ID: P_Michalik_20130729-M-4.1; https://www.morphdbase.de?P_ Michalik_20130729-M-4.1). 


\section{Abbreviations}

$\begin{array}{ll}\text { ALE } & \text { anterior lateral eye } \\ \text { AME } & \text { anterior median eye } \\ \text { bH } & \text { basal hematodocha } \\ \text { Cb } & \text { cymbium } \\ \text { Ch } & \text { chelicera } \\ \text { E } & \text { embolus } \\ \text { HSt } & \text { hook of subtegulum } \\ \text { m29 } & \text { muscle 29 } \\ \text { m30 } & \text { muscle 30 } \\ \text { mA } & \text { median apophysis } \\ \text { mH } & \text { median hematodocha } \\ \text { MOQ } & \text { median ocular quadrangle } \\ \text { PLE } & \text { posterior lateral eye } \\ \text { PME } & \text { posterior median eye } \\ \text { PSt } & \text { process of subtegulum } \\ \text { S } & \text { spermophor } \\ \text { St } & \text { subtegulum } \\ \text { Te } & \text { tegulum } \\ \text { tm29 } & \text { tendon of muscle 29 } \\ \text { tm30 } & \text { tendon of muscle 30 } \\ \text { ZIMG } & \text { Zoologisches Institut und Museum Greifswald (Germany) }\end{array}$

\section{Taxonomy}

Family Austrochilidae Zapfe 1955

Subfamily Austrochilinae Zapfe 1955

Genus Thaida Karsch 1880

Thaida chepu Platnick, 1987

http://species-id.net/wiki/Thaida_chepu

Material examined. CHILE: Region de Los Lagos (X), Chiloé province, Isla de Chiloé, Lago Huillinco, N margin, $4.6 \mathrm{~km}$ (air) ESE Cucao, S42.64117 , W74.04763 (GPS, $\pm 100 \mathrm{~m}$ ), elev. $12 \mathrm{~m}$ (MJR-loc-86), 16 February 2012, 1 male, coll. K. Huckstorf, M. Izquierdo, P. Michalik, M. J. Ramirez, C. S. Wirkner (ZIMG II/28126).

Diagnosis. Similar to T. peculiaris by the clypeus about three times the diameter of the anterior median eyes (Fig. 3); males distinguished from T. peculiaris by the copulatory bulb, which has the median apophysis longer than the embolus (Figs 5-10; about half the length of the embolus in T. peculiaris, Forster et al. 1987, figs 155-157), a stout and curved 

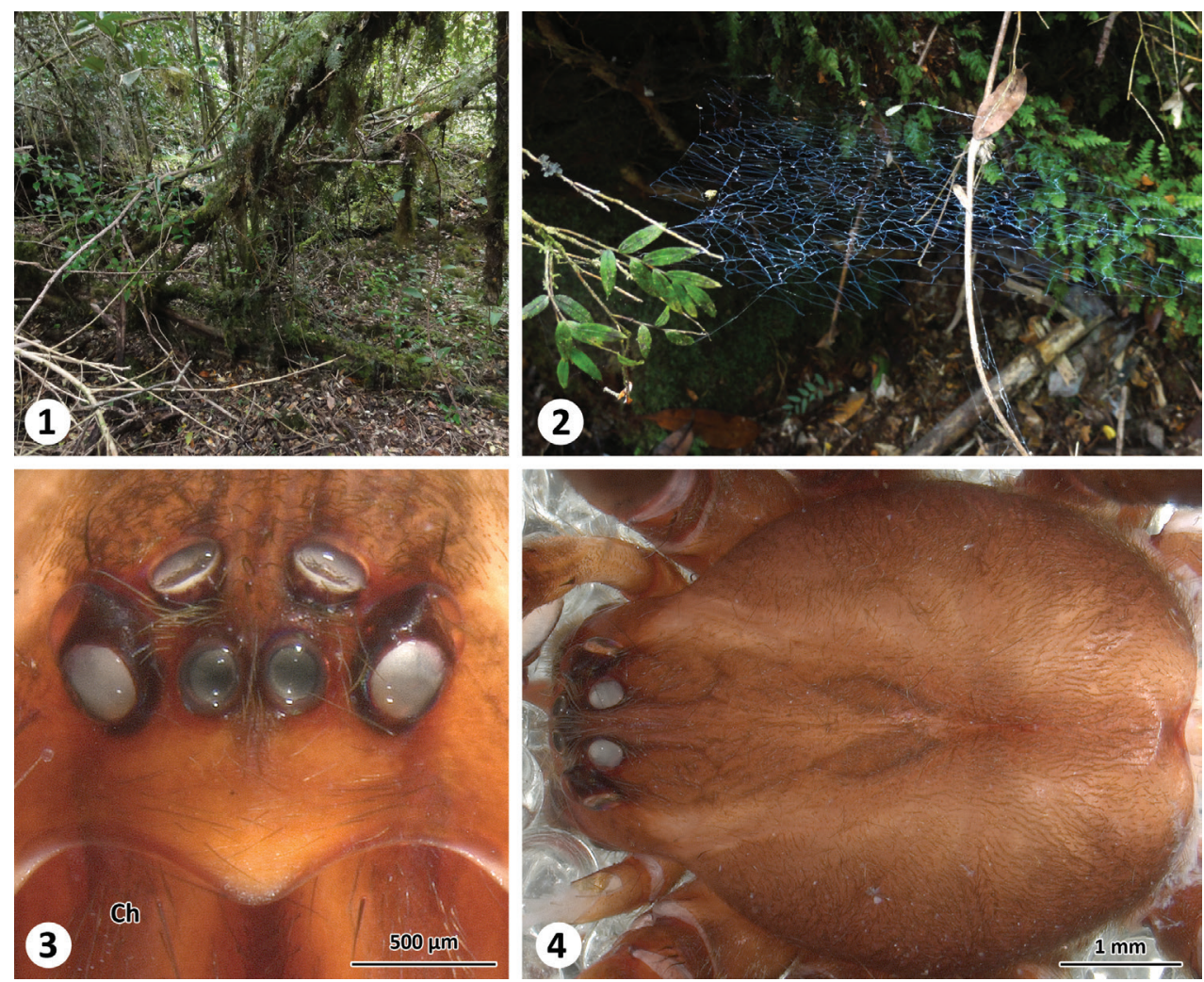

Figure I-4. Habitat (I), web (2) and somatic characters (frontal (3) and dorsal (4) view of prosoma) of Thaida chepu.

process of the subtegulum (slender and straight in T. peculiaris, Forster et al. 1987, figs 155-157), and the bent embolus with a curved tip (embolus of $T$. peculiaris without distinct tip, Forster et al. 1987, figs 155-157). Diagnosis of the female in Forster et al. (1987).

Description. Male (ZIMG II/28126). Carapace 5.59 long and 4.38 wide; clypeal height 0.68 (in the middle about three times AME diameter in height; Fig. 3); coloration as depicted in Fig. 4. Eye sizes and interdistances: AME 0.24, ALE 0.31, PME 0.25, PLE 0.30; AME-AME 0.05, AME-ALE 0.15, PME-PME 0.26, PMEPLE 0.22, ALE-PLE 0.06; MOQ length 0.77, median ocular quadrangle width 0.78. Spination: femora: I d 1-0-1, p 2-3-3, r 2-3-3; II d 1-2-1, p 2-2-2, r 2-2-2; III d 1-2-1, p 1-2-2, r 2-2-2; IV d 2-2-1, p 0-1-2, r 0-1-3; tibiae: I p 2-3-2, v 3-3-4, r 2-2-2; II p 2-2-2, v 3-4-3, r 1-1-2; III d 1-0-1, p 0-2-2, v 1-1-4, r 0-2-1; IV missing; metatarsus: I p 3-1-2, v 1-1-1, r 2-2-2; II d 0-1-2, p 1-2-2, v 0-1-2, r 1-1-0; III p 1-1-2, v 2-3-2, r 2-2-1; IV missing. Palp (Figs 5-10): cymbium slender, median apophysis slender and spine-shaped with serrated tip, embolus broad with twisted, membranous flange and slit-like opening, membranous spermophor as depicted in Figs $8-10, \mathrm{~m} 29$ and $\mathrm{m} 30$ originating in tibia. The $3 \mathrm{D}$ reconstruction revealed that the spermophor fills most of the subtegulum and is flattened and thin within the embolus (Video 1). Abdomen missing. 

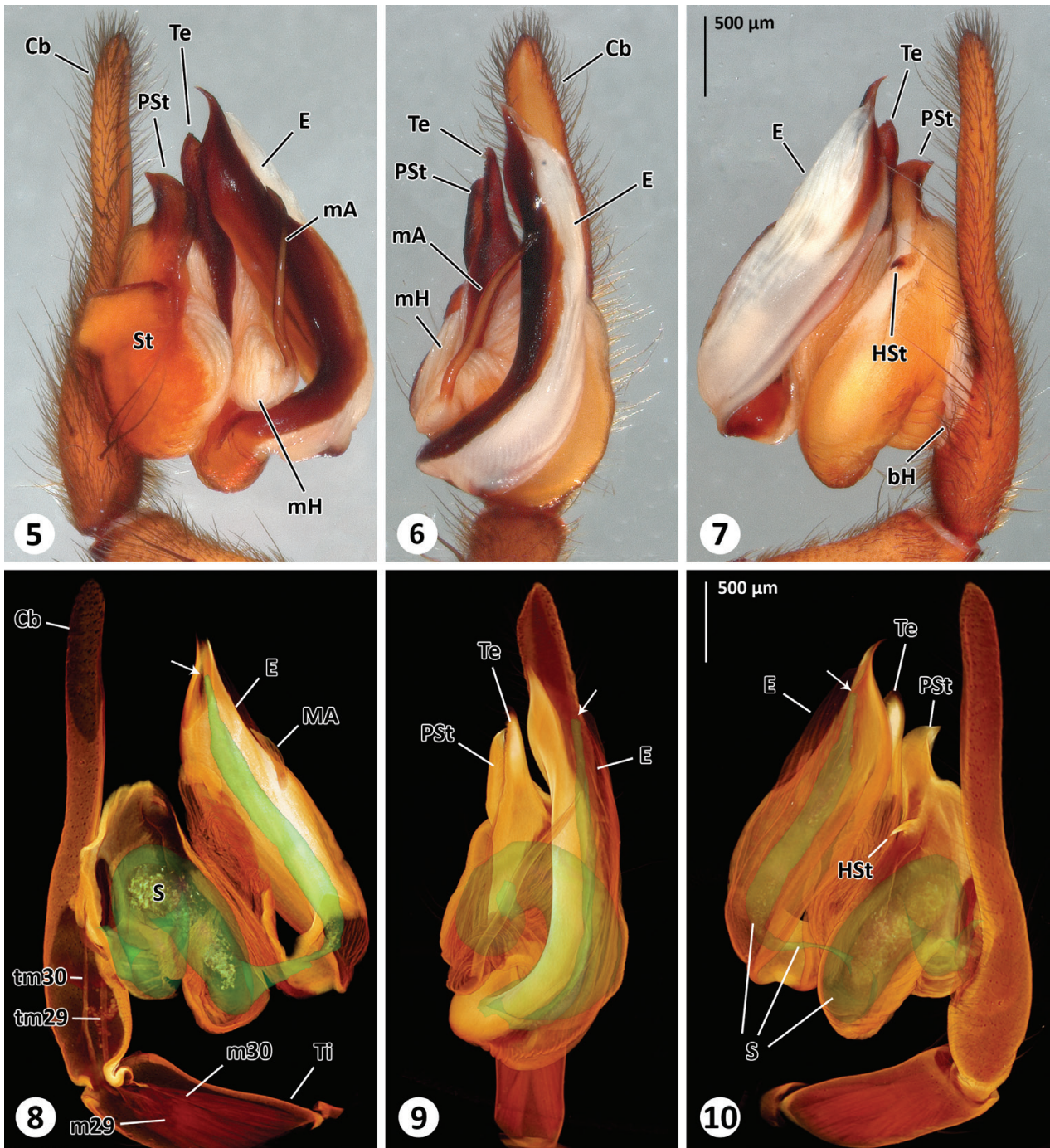

Figure 5-10. Left male palp of Thaida chepu. 5-7 extended focal plane images of male palp in prolateral (5), ventral (6) and retrolateral (7) view 8-10 surface model of the spermophor superimposed on the volume rendering of the male palp to illustrate dimension and shape of the spermophor. The views correspond to Figs 5-7. The cymbium, subtegulum and tegulum are (partly) removed in Fig. 8 to show tendons and muscles. The arrows point to the opening of the embolus.

\section{Appendages measurements:}

\begin{tabular}{l|l|l|l|l|l}
\hline & I & II & III & IV & Palp \\
\hline Femur & 8.82 & 7.67 & 5.95 & 7.3 & 2.99 \\
\hline Patella & 2.02 & 1.83 & 1.54 & 1.69 & 0.92 \\
\hline Tibia & 9.91 & 7.55 & 4.63 & missing & 1.43 \\
\hline Metatarsus & 9.40 & 7.60 & 5.39 & missing & - \\
\hline Tarsus & 3.68 & 3.04 & 2.17 & missing & 3.27 \\
\hline Total & 33.84 & 27.71 & 19.69 & & 8.62 \\
\hline
\end{tabular}




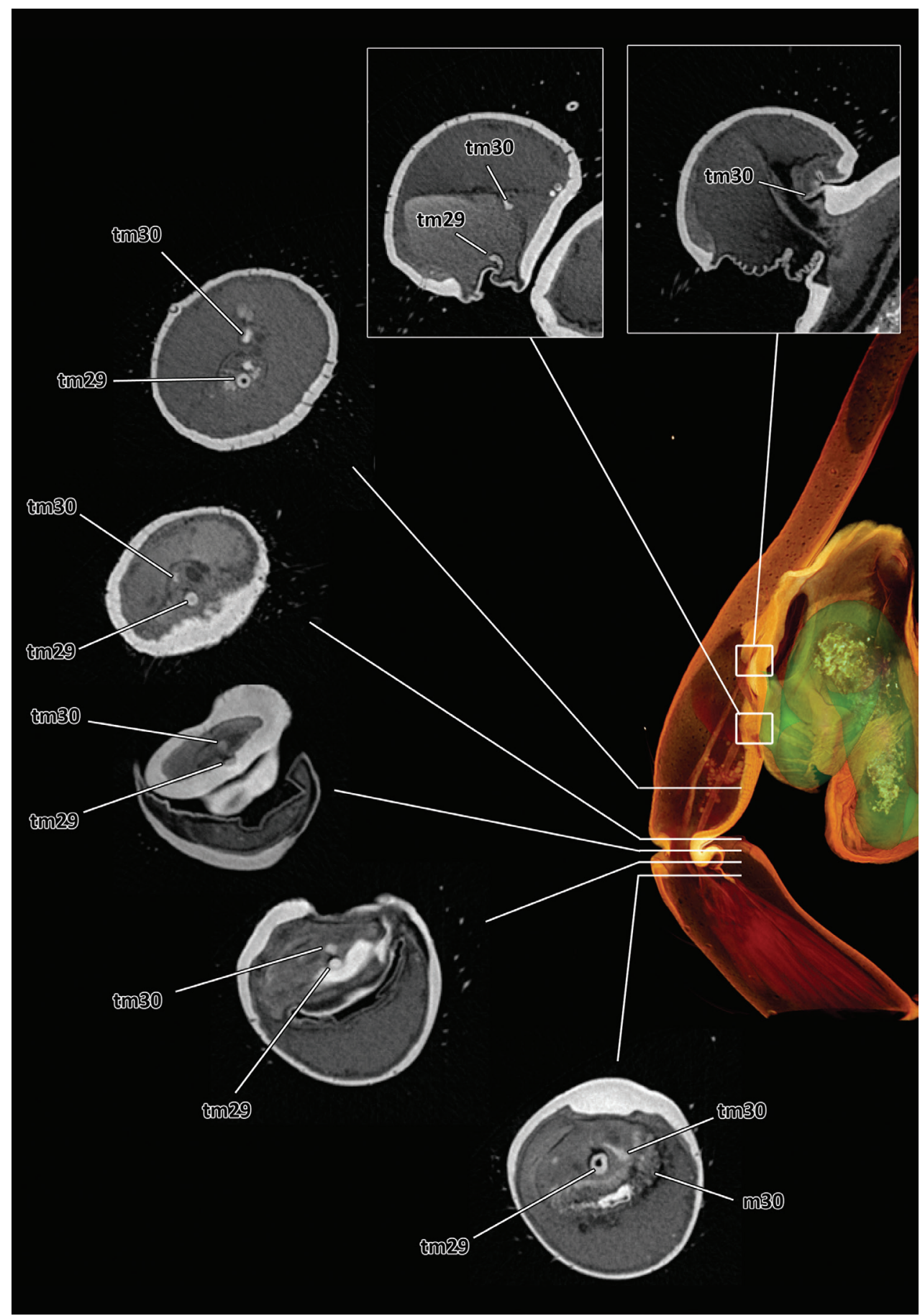

Figure I I. Series of virtual cross sections through the left male palp of Thaida chepu showing the course of the two tendons. 


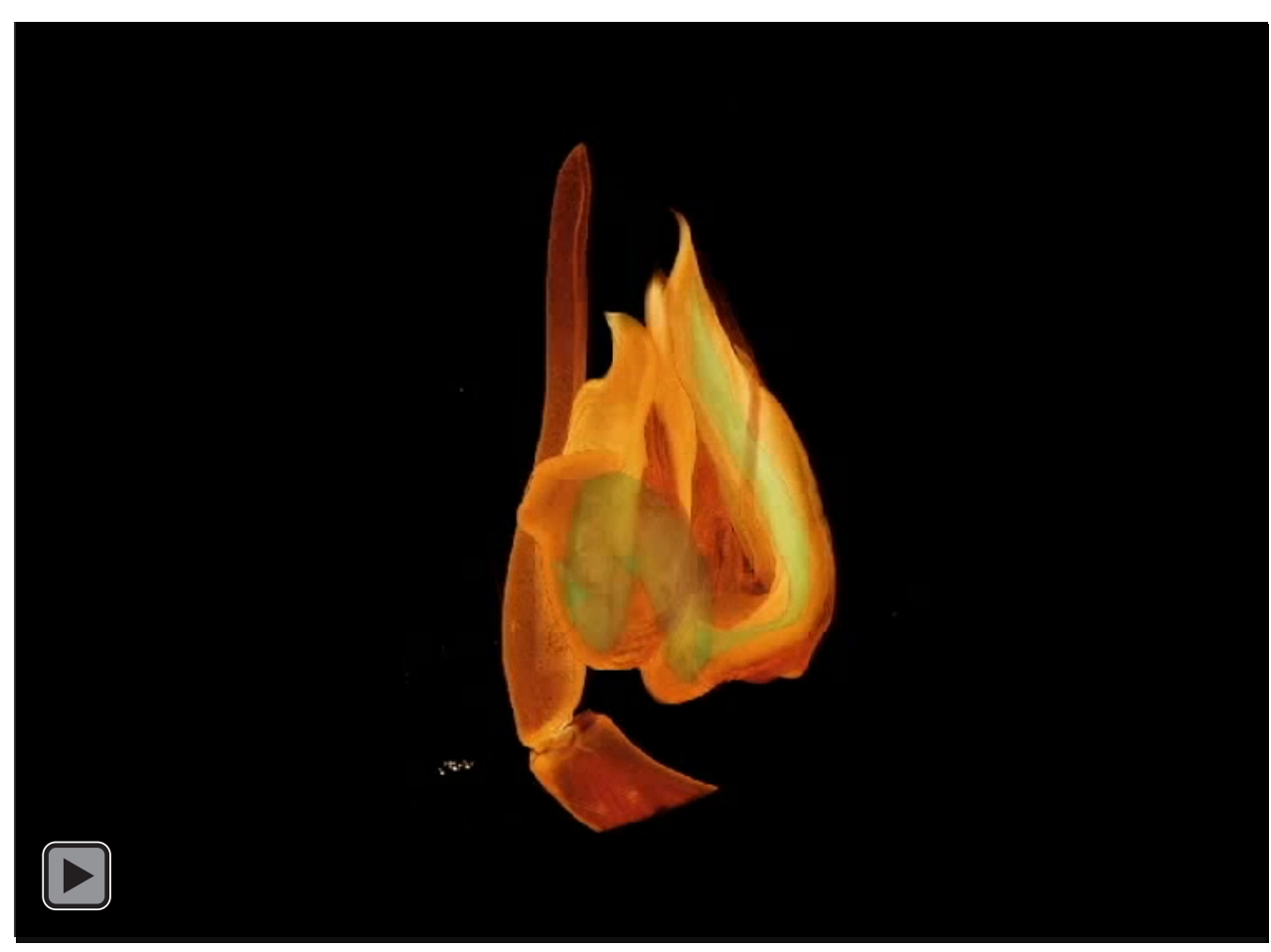

Video I. Surface model of the spermophor superimposed on the volume rendering of the male palp. Video available for download in full resolution from http://www.pensoft.net/J_FILES/1/articles/6021/ export.php_files/Michalik_Ramirez_Video_1.avi.

Natural history. The webs of $T$. chepu are very similar to those described for Thaida peculiaris Karsch 1880 and Austrochilus forsteri Grismado, Lopardo \& Platnick, 2003 by Lopardo et al. (2004) (Fig. 2).

\section{Discussion}

Based on the micro-CT data and manual segmentation of the spermophor we confirm the interpretation of the male palp sclerites especially with regard to the position of the embolus given by Griswold et al. (2005). The spermophor of austrochilines is membranous, with thin cuticle, not evident without preparation (e.g., micro-CT or clearing by clove oil; see also Huber 2004). Moreover and in contrast to the findings of Huber (2004) on T. peculiaris, our micro-CT analysis revealed that no muscles originate in the cymbium (tarsus) of T. chepu. Instead, the muscles 29 and 30 originate in the tibia and are connected by tendons with the bulbal sclerites (Figs 8, 11) - an organization only known from the basal spider genera Liphistius Schiödte, 1849 and Atypus Latreille, 1804 (Huber 2004). Preliminary micro-CT analyses of the palp 
of the sister group Hickmaniinae ( $H$. troglodytes) (Lipke, personal communication), histological sections as well as micro-CT analyses of representatives of Gradungulidae (Huber 1994; Michalik et al. 2013) and Hypochilus (Hypochilidae) (Huber 1994) revealed that the muscle 30 originates in the cymbium as typical for araneomorph spiders (Huber 2004). This is especially important since austrochilids are key taxa that might reveal important information to interpret the transition from muscular to hydraulically-controlled copulatory organs (Huber 2004), and towards the evolution of higher Araneomorphae (i.e. Haplogynae and Entelgynae).

As shown here micro-CT data can be used for precise and transparent descriptions (for details on the method and data handling see Faulwetter et al. 2013) as well as revealing internal anatomical characters useful for spider taxonomy, systematics and evolutionary/functional morphology.

\section{Acknowledgments}

We thank Christian Wirkner and Katharina Huckstorf (University Rostock, Germany) as well as Matias Izquierdo (MACN, Buenos Aires, Argentina) for sharing a fantastic time in the field. We thank Elisabeth Lipke (University Greifswald, Germany) for her help with the 3D data processing and Bernhard Huber (ZMFK Bonn, Germany) for helpful comments on the manuscript. This study was funded by the German Science Foundation (DFG Mi 1255/5-1), CONICET (PIP 112-200801-03209), ANPCyT (FONCyT, PICT-2007-01393) and the University of Greifswald (Germany). The material was collected under CONAF permit 027/2011.

\section{References}

Faulwetter S, Vasileiadou A, Kouratoras M, Dailianis T, Arvanitidis C (2013) Micro-computed tomography: Introducing new dimensions to taxonomy. Zookeys 263: 1-45. doi: 10.3897/zookeys.263.4261

Forster RR, Platnick NI, Gray MR (1987) A review of the spider superfamilies Hypochiloidea and Austrochiloidea (Araneae, Araneomorphae). Bulletin of the American Museum of Natural History 185: 1-116.

Grismado CJ, Lopardo L, Platnick NI (2003) A new species of Austrochilus from Chile (Araneae, Austrochilidae, Austrochilinae). Journal of Arachnology 31: 148-150. doi: 10.1636/0161-8202(2003)031[0148:ANSOAF]2.0.CO;2

Griswold CE, Ramírez MJ, Coddington JA, Platnick NI (2005) Atlas of Pylogenetic Data for Entelegyne Spiders (Araneae: Araneomorphae: Entelegynae) with Comments on Their Phylogeny. Proceedings of the California Academy of Sciences 56: 1-325.

Huber BA (1994) Genital bulb muscles in entelegyne spiders. Journal of Arachnology 22: $75-76$. 
Huber BA (2004) Evolutionary transformation from muscular to hydraulic movements in spider (Arachnida, Araneae) genitalia: a study based on histological serial sections. Journal of Morphology 261: 364-376. doi: 10.1002/jmor.10255

Lopardo L, Ramirez MJ, Grismado C, Compagnucci LA (2004) Web building behavior and the phylogeny of austrochiline spiders. Journal of Arachnology 32: 42-54. doi: 10.1636/H02-45 Michalik P, Piacentini L, Lipke E, Ramirez MJ (2013) The enigmatic Otway odd-clawed spider (Progradungula otwayensis Milledge, 1997, Gradungulidae, Araneae): Natural history, first description of the female and micro-computed tomography of the male palpal organ. Zookeys 335: 101-112. doi: 10.3897/zookeys.335.6030 